Hülya Yiğit Özay

Elif Bombacı

Güneş Çobanoğlu Ercan

Serhan Çolakoğlu

\title{
Yoğun Bakım Ünitesine Tekrar Yatış Yapılan Olguların Geriye Dönük Analizi; Nedenleri, Sonuçları ve Mortaliteyi Etkileyen Faktörlerin Değerlendirilmesi
}

\author{
Retrospective Analysis of the Re-Admitted Cases in \\ Intensive Care Unit; Reasons, Outcomes and \\ Evaluation of the Factors That Affect Mortality
}

Geliş Tarihi/Received: 20.11.2012

Kabul Tarihi/Accepted: 28.12.2012

Türk Yoğun Bakım Derneği Dergisi, Galenos Yayınevi tarafindan basilmıștı.

Journal of the Turkish Society of Intensive Care, published by Galenos Publishing.

ISNN: 1300-5804

Hülya Yiğit Özay, Elif Bombacı (凶), Güneș Çobanoğlu Ercan, Serhan Çolakoğlu

Dr. Lütfi Kırdar Kartal Eğitim ve Araştırma Hastanesi Anesteziyoloji ve Reanimasyon Kliniği, Istanbul, Türkiye

E-posta: bombaciel@yahoo.com

Tel.: +90 21644139 00/ 1273-1245
ÖZET Amaç: Çalışmanın amacı Yoğun Bakım Ünitesi (YBÜ)'sinde tekrarlayan yatışların nedenleri ve sonuçlarını analiz etmektir. Ayrıca bu hasta grubunda mortaliteyi etkileyen faktörler incelenmiştir. Gereç ve Yöntem: Temmuz 2007- Haziran 2010 tarihleri arası hastanemiz YBÜ'de takip ve tedavi edilen hastaların kayıtları geriye dönük olarak incelendi. Yeniden yatış endikasyonları, iki yatış arası zaman ve tekrar yatışların sonuçları belirlendi.

Bulgular: Üç ylllık sürede 2011 hasta tedavi edilmişti. Bu hastaların 68'ine $(\% 3,38)$ tekrar yatış verilmişti. Bu hastaların 33'üne (\%49) aynı, 35 'ine (\%51) ise farklı endikasyon ile YBÜ'ne yatış verilmişti. Tekrar yatışların 10'u $(\% 14,7)$ ilk 48 saatte YBÜ'ne tekrar kabul edilmiş olup bu hastaların 7'si (\%70) eksitus olurken 48 saatten geç yatışlarda bu oran $\% 30$ idi. Veriler gösterdi ki; tekrar yatışta mekanik ventilasyon uygulanan 53 hastanın 12'si (\%23) ilk yatışlarında "weaning" tamamlandıktan sonraki ilk 24 saatte taburcu edilmişlerdi. Erken tekrar yatışlarda mortalite oranı geç tekrar yatışlara göre anlamlı olarak yüksek bulundu.

Sonuç: Hastanın 'weaning' tamamlandıktan sonra 24 saatten daha uzun süre YBÜ'de takip edilmesiyle tekrar yatış oranının azaltılabileceği kanaatindeyiz. Bu hastaların YBÜ çıkış kriterleri stabil oluncaya kadar 'yakın bakım üniteleri'ne çıkarıması daha iyi olacaktır.

Anahtar Kelimeler: Tekrarlayan yatış, yoğun bakım ünitesi
SUMMARY Objective: The purpose of the study to analyze the reasons and outcomes of re-admission in the intensive care unit (ICU). And also, the factors, which affect mortality in this group of patients, were studied. Material and Method: The registry of patients, who were re-admitted in ICU between July 2007 and June 2010 in our hospital, were analysed retrospectively. The data about indications of re-admission, the time between two admissions and the outcomes of the second admission, have been gathered. Results: 2011 patients were treated in three years' period. Sixty-eight of them (3.38\%) were re-admitted to ICU. Thirty-three of these patients (49\%) were re-admitted to ICU with the former indications, 35 (51\%) with a different indications. Ten (14.7\%) of the patients who were discharged from ICU, readmitted in the first 48 hours. While seven of the patients $(70 \%)$ who were re- admitted in the first 48 hours after discharge were died. Seventeen of patients (30\%) who were readmitted after 48 hours were lost. The data revealed that, $12(23 \%)$ of the 53 patients who were mechanically ventilated among the readmitted cases were discharged in the first 24 hours after weaning completed in their first admission. The mortality rate in the early readmitted patiens were significantly higher than in the late re-admitted ones.

Conclusion: We believe that the rate of readmission can be reduced if patients keep in the ICU more than 24 hours after weaning. The better, to monitor the patients in the "close care units" before discharge, until the discharging criteria become steadier.

Key Words: Re-admission, intensive care unit 


\section{Giriş}

Ortalama yaşam süresinin artması, malignite tedavilerindeki gelişmeler, cerrahi ve diğer tanısal tetkiklerdeki ilerlemeler, toplumun beklentilerini artırmış, sonuç olarak; Yoğun Bakım Üniteleri (YBÜ)'inde ileri yaşlı ve karmaşık yandaş hastalıkları olan hastalar tedavi görmeye başlamıştır.

Hasta açısından oldukça yıpratıcı ve maliyeti yüksek tedavi protokolleri içeren yoğun bakım sürecinde, bazı hastaların üniteye tekrarlayan yatışları söz konusu olabilmektedir. Bu durum gerek çalışanlar, gerekse hasta ve hasta yakınları için maddi- manevi yüke neden olmaktadır.

Bu çalışmada amaç; yoğun bakım ünitelerimizde tekrarlayan yatışların nedenlerini, sonuçlarını incelemek ve mortaliteyi etkileyen faktörleri belirlemektir.

\section{Gereç ve Yöntem}

Çalışmamızda hastanemiz Anesteziyoloji ve Reanimasyon Klinikleri YBÜ'lerinde Temmuz 2007 - Haziran 2010 tarihleri arasında takip ve tedavi edilen hastaların yoğun bakıma tekrar yatışları geriye dönük olarak incelendi.

Hastaların demografik özellikleri, birinci ve tekrar yatışlarda hasta sayısının yıllara göre dağılımı, tekrar yatış oranları, hastaların yatış endikasyonları ve yandaş hastalıkları, tekrar yatışların endikasyonlarına göre dağılımı, birinci ve tekrar yatışlarda YBÜ'den çıkış durumuna göre hastaların değerlendirilmesi, YBÜ'ye tekrar yatışın zamanı (taburcu sonrası ilk 48 saat içinde ise erken yatış, 48 saatten sonra ise geç yatış), mekanik ventilasyon ihtiyacına göre hastaların dağılımı, YBÜ'ye tekrar yatışı olan hastaların birinci kabullerinde "weaning" sonrası taburcu olma zamanı, birinci ve tekrar yatışlarda mortalite-YBÜ yatış günü ilişkisi, birinci ve tekrar yatışlarda mortalite oranları, hastaların YBÜ'ye ilk ve tekrar yatışındaki Glasgow koma skoru, APACHE II skoru ve SOFA skoru, tüm yatışlarda ölüm yeri (yoğun bakım ya da hastanede) incelenerek kayıt edildi.

Verilerin istatistiksel analizleri için NCSS 2007 (Statistical Analysis Graphics) paket programı kullandı. Tanımlayıcı istatistiksel metotların (ortalama, standart sapma) yanı sıra, ikili grupların karşılaştırmasında bağımsıı t testi, verilerin karşılaştırmalarında ki-kare testi, bağımlı değişken ile bir veya daha çok bağımsız değişken arasındaki ilişkiyi incelemek amacıyla regresyon testi, normal dağılım göstermeyen parametrelerin gruplar arası karşılaştırmalarında Kruskal-Wallis testi ve farklılığa neden olan grubun tespitinde Mann-Whitney $U$ testi, normal dağılım gösteren parametrelerin grup içi karşılaştırmalarında eşleştirilmiş örneklem t testi, normal dağılım göstermeyen parametrelerin grup içi karşılaştırmalarında ise Wilcoxon işaret testi ve niteliksel verilerin karşılaştııımasında ise ki-kare testinden faydalanıldı. Sonuçlar \%95'lik güven aralığında, anlamlıık $p<0,05$ düzeyinde değerlendirildi.

\section{Bulgular}

Hastanemizin yoğun bakım ünitelerinde üç yıllık süreçte takip edilen 2011 hastanın 68'inin (\%3,38) tekrar yatışı olmuştur. Birinci yatışların 1116'ı (\%55,49) erkek, 895'i $(\% 44,51)$ kadın, ikinci yatışların 39'u $(\% 57,35)$ erkek, 29'u $(\% 42,65)$ kadın hasta olup her iki grupta da cinsiyet dağılımına göre istatistiksel olarak anlamlı fark bulunmadı (p>0,05). Illk yatışlarda yaş ortalaması $46,07 \pm 25,88$ yıl, tekrar yatışlarda 51,39 $\pm 25,31$ yıl olup fark istatistiksel olarak anlamlı değildi ( $p>0,05)$.

Hastaların yaşa göre dağılımını incelemek için hastalar dekatlara göre gruplandıııld. Hasta yaş gruplarında ise 8., 7. ve 1. dekatta bulunan hasta sayısı (sırasıyla 333, 269 ve 254 hasta) en fazlaydı.

- Hasta Sayılarının Yıllara Göre Dağılımı:

Hastanemizin yoğun bakım yatak sayısı 2007 yılında 15 iken, 2008 yılında 10 yataklı yeni bir yoğun bakım ünitesinin açılıasıyla 25 'e yükselmiştir. Buna paralel olarak üç yıllık sürecin birinci yılında hasta yatış oranlarının en az, üçüncü yılda en fazla olduğu, tekrarlayan yatışlar karşılaştııılığında ise üç yıllık süreçte yeniden yatış oranının giderek azaldığı tespit edildi (Tablo 1).

- Hastaların Yatış Endikasyonları ve Yandaş Hastalıkları:

Yatış endikasyonlarının yıllara göre dağılımında; postoperatif bakım amaçlı yatışlar her üç yılda birinci sırada yer alırken ilk iki yıl ikinci ve üçüncü sırayı zehirlenmeler ve trafik kazaları paylaşmıştı (Tablo 2). Üçüncü yılda ise $\mathrm{KOAH}$ ve akut solunum yetmezliği üçüncü sıraya yerleşmişti. En sık görülen yandaş hastalık \%48.74'lik oranıyla hipertansiyon ve diğer kardiyak hastalıklar, ikinci sırada endokrin hastalıklar (diabetes mellitus, \%18.53) saptandı (Tablo 3).

- Yoğun Bakım Ünitesi'ne Tekrar Yatan Hastaların Değerlendirilmesi:

Takip edilen 2011 hastadan 68'i $(\% 3,38)$ yeniden YBÜ'ne yatırılmış olup bu hastaların 33'ünün (\%49) aynı nedenle, 35'inin

Tablo 1. Hasta sayılarının yıllara göre dağılımı

\begin{tabular}{lccccc}
\hline & ilk Yatış & \% oran & Tekrar yatış & \% oran & Tekrar yatış (\%) \\
\hline 1. yıl & 370 & 18,40 & 16 & 24,24 & 4,15 \\
2. yll & 765 & 38,04 & 25 & 36,36 & 3,16 \\
3. yll & 876 & 43,56 & 27 & 39,39 \\
Toplam & 2011 & 100,00 & 68 & 100,00
\end{tabular}


Tablo 2. Hastaların yatış endikasyonlarının yıllara göre dağılımı [n (\%)]

\begin{tabular}{|c|c|c|c|c|}
\hline TANILAR & 1.YIL & 2.YIL & 3.YIL & TOPLAM \\
\hline Postoperatif & $90(24,32)$ & $164(21,44)$ & $220(25,11)$ & $474(23,57)$ \\
\hline İntoksikasyon & $45(12,16)$ & $73(9,54)$ & $94(10,73)$ & $212(10,54)$ \\
\hline isH / SVO & $35(9,46)$ & $65(8,50)$ & $72(9,36)$ & $182(9,05)$ \\
\hline Diğer nörolojik hastalık & $24(6,49)$ & $42(5,49)$ & $40(4,57)$ & $106(5,27)$ \\
\hline Başarilı KPR & $23(6,22)$ & $41(5,36)$ & $39(4,45)$ & $103(5,12)$ \\
\hline Yüksekten düşme & $18(4,86)$ & $30(3,92)$ & $54(6,16)$ & $102(5,07)$ \\
\hline Diğer dahili hastalıklar & $13(3,51)$ & $38(4,97)$ & $46(5,25)$ & $97(4,82)$ \\
\hline $\mathrm{KOAH}$, akut sol, yetm & $12(3,24)$ & $40(5,23)$ & $82(9,39)$ & $134(17,86)$ \\
\hline Akciğer ödemi & $8(2,16)$ & $15(1,96)$ & $6(0,68)$ & $29(1,44)$ \\
\hline $\mathrm{MA} / \mathrm{EI}$ & $7(1,89)$ & $7(0,92)$ & $15(1,71)$ & $29(1,44)$ \\
\hline Şok & $2(0,54)$ & $8(1,05)$ & $8(0,91)$ & $18(0,90)$ \\
\hline Yanık & $1(0,27)$ & $7(0,92)$ & $1(0,11)$ & $9(0,45)$ \\
\hline Darp & $0(0,00)$ & $1(0,13)$ & $2(0,23)$ & $3(0,15)$ \\
\hline Suda boğulma & $0(0,00)$ & $2(0,26)$ & $0(0,00)$ & $2(0,10)$ \\
\hline DiK & $0(0,00)$ & $3(0,39)$ & $0(0,00)$ & $3(0,15)$ \\
\hline Ası & $0(0,00)$ & $0(0,00)$ & $1(0,11)$ & $1(0,05)$ \\
\hline TOPLAM & 370 & 765 & 876 & 2011 \\
\hline
\end{tabular}

iSH: İntraserebral hemoraji, SVO: Serebro-vasküler olay, KPR: Kardiyopulmoner resüsitasyon, ÇOY: Çoklu organ yetmezliği, MA: Metabolik asidoz, El: Elektrolit imbalansı,

KOAH: Kronik obstrüktif akciğer hastalığı, DiK: Dissemine intravasküler koagülasyon

Tablo 3. Yandaş hastalıklara göre hasta dağııımı

\begin{tabular}{lcc}
\hline Yandaş hastalıklar & Hasta sayısı & Tüm yatışlara göre \% \\
\hline Kardiyak hastalık & 618 & 48,74 \\
Endokrin hastalık & 235 & 18,53 \\
Astım/KOAH & 144 & 11,36 \\
Nörolojik hastalık & 121 & 9,54 \\
Renal hastalık & 76 & 5,99 \\
Malignite & 56 & 4,42 \\
Psikiyatrik hastalık & 18 & 1,42
\end{tabular}

Tablo 4. Tekrar yatışların endikasyonlarına göre dağıımı

\begin{tabular}{lcc}
\hline Tanı & Hasta Sayısı & Yüzde \% \\
\hline Solunum yet. & 20 & 30 \\
Postoperatif & 15 & 22 \\
Pnömoni & 9 & 13 \\
KOAH & 8 & 12 \\
Sepsis & 4 & 6 \\
Status epileptikus & 4 & 6 \\
Intraserebral hemoraji & 3 & 4 \\
KBY (elektrolit imbalansı) & 2 & 3 \\
Intoksikasyon (Tekrar intihar) & 2 & 3 \\
Larinks ödemi & 1 & 1 \\
TOPLAM & 68 & 100
\end{tabular}

(\%51) ise farklı nedenle YBÜ'ye yatışının olduğu görüldü. En sık tekrar yatış endikasyonlarının ise akut solunum yetmezliği (\%30) ve postoperatif bakım (\%22) olduğu tespit edildi (Tablo 4). Ikinci yatış nedeni 'postoperatif bakım' olarak tanımlanmış olgular, yoğun bakımdan ilgili kliniğe devredildikten bir süre sonra ilgili patolojileri nedeniyle elektif cerrahi geçiren ve tedbir amaçlı YBÜ'ne tekrar yatırılan olgular idi.

- Birinci ve Tekrar Gelişlerde YBÜ'den Çıkış Durumları:

YBÜ'ne birinci ve tekrar yatışlar kendi aralarında karşılaştırıldı. Ilk gelişlerde hasta sayıları değerlendirildiğinde kadın ve erkek gruplarındaki hastaların evine ya da başka bir servise taburcusu, eksitus olması, çeşitli nedenlerle başka bir hastanenin YBÜ'ne sevk olmasına göre gruplar benzerdi. Erken ve geç tekrar gelişlerdeki taburcu ve eksitus oranları arasında ileri derecede anlamlı fark bulundu $(p<0,001)$. Tekrar gelen 68 hastanın 10'u ilk 48 saatte yoğun bakıma tekrar kabul edilmiş olup bu hastaların 7'si (\% 70) eksitus olurken geç yatışlarda bu oran \%30 idi (Grafik 1).

- Mekanik Ventilasyon Ihtiyacına Göre Hasta Dağılımı:

Hastaların yoğun bakım takip ve tedavileri sırasında \%78,37'sinin mekanik ventilasyon (MV) desteğine ihtiyacı oldu. Hem ilk yatış hem de tekrar yatışlarda erkek hastalarda MV ihtiyacı daha fazlaydı. Altmış sekiz hastanın 15 'inde (\%22) 
MV ihtiyacı olmadı. MV ihtiyacı olan 53 hastanın, ilk yatışı ve tedavisinde mekanik ventilasyondan ayrıldıktan sonraki taburcu olma sürelerine bakıldı. Tekrar yatış verilen hastaların \%23'ünün (12 hasta) ilk yatışlarında "weaning" tamamlandıktan sonraki ilk 24 saatte taburcu oldukları görüldü (Tablo 5 ve 6).

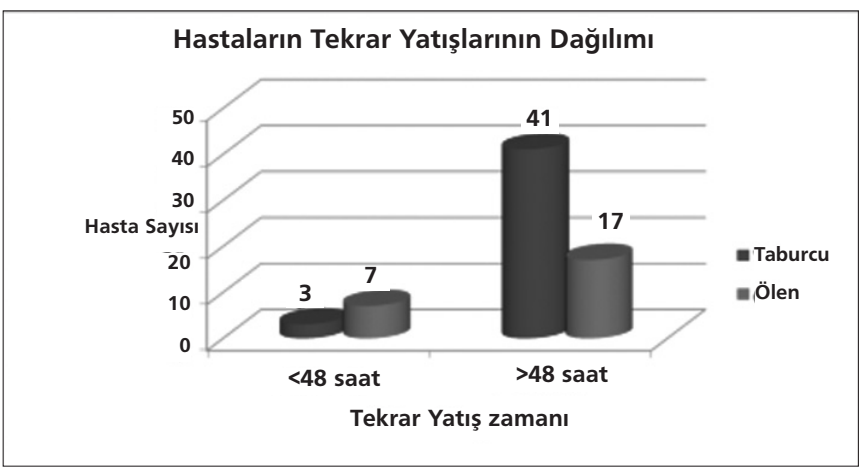

Grafik 1. Hastaların tekrar yatışlarındaki YBÜ çıkış durumlarının dağıımı

Tablo 5. Birinci ve tekrar yatışlarda mekanik ventilasyon (MV) intiyacına göre hasta dağılımı

\begin{tabular}{lcc}
\hline & \multicolumn{2}{c}{ Hasta Sayısı } \\
& ilk Yatış (\%) & Tekrar Yatış (\%) \\
\hline MV ihtiyacı olan & $1576(\% 78,37)$ & $53(\% 78)$ \\
MV ihtiyacı olmayan & $435(\% 21,63)$ & $15(\% 22)$ \\
Toplam & 2011 & 68
\end{tabular}

Tablo 6. YBÜ'ne tekrar yatışı olan hastaların ilk kabullerinde "weaning" sonrası taburcu olma zamanı

\begin{tabular}{lc}
\hline Taburcu olma günü & Hasta sayısı (\%) \\
\hline 24 saat içinde & $12(\% 23)$ \\
$1-2$ gün & $14(\% 27)$ \\
$3-4$ gün & $10(\% 19)$ \\
$5-10$ gün & $8(\% 14)$ \\
11 ve üzeri & $9(\% 17)$
\end{tabular}

- Tekrar yatışlarda Mortalite-YBÜ Yatış Günü lisşkisi:

YBÜ'ne birinci gelişlerde ortalama yatış günü $6,81+12,71$, erken tekrar gelişlerde 11,12+17,30, geç tekrar gelişlerde $8,57+10,84$ gün idi. Hastaların YBÜ'nde yatış gün sayısına göre taburcu olan ve ölen hasta sayıları benzer bulundu. Yoğun bakımda yatış günü en az 1 gün, en fazla 193 gün idi. Ölüm oranının en yüksek olduğu yatış günü ilk 48 saate kadar olan yatışlar olup bunların tüm ölen hastalara oranı \%14,72 idi. Tekrar yatışlarda 3.5. günlerde başka bir servise taburcu olma oranları en fazla olmakla beraber en yüksek ölüm oranı ilk 48 saatte idi (Tablo 7).

- Mortalite Oranları:

YBÜ'nde takip ve tedavi edilen 2011 hastanın 1219' u taburcu, 792'si eksitus olup mortalite \%39,38 olarak saptand. Taburcu edilen hastaların ise 44 'ü $(\% 3,48)$ devredildiği klinikte kaybedildi. Erken tekrar gelişlerde mortalite \%70 olup geç tekrar gelişlerde tespit edilen mortalite oranından $(\% 29,31)$ istatistiksel olarak anlamlı derecede yüksek bulundu $\left(\chi^{2}=53\right.$ $p=0,00001<0,01$ ) (Tablo 8).

- Ilk ve Tekrar Yatışlarda Mortalite-Morbidite Skoru karşılaştırılması:

Tekrar yatıştaki ortalama APACHE II değerlerinin ölen hastalarda ilk yatış ortalamalarından anlamlı, taburcu olan hastaların ise ilk yatış ortalamalarından anlamsız yüksek olduğu görüldü (sırasıyla $t=3,25 p=0,0022$ ve $t=1,54 p=0,12$ ). Ölen ve taburcu olan hastaların SOFA değerleri de ilk ve tekrar yatışlarda benzer değişiklik göstermekteydi (sırasıyla $t=4,34 \quad p=0,000073$ ve $t=1,89 p=0,061)$. Ölen ve taburcu olan hastaların tekrar gelişteki ortalama GKS değerlerinin ilk geliş ortalamalarıyla karşılaştırımasında ise anlamlı fark bulunmadı (p>0,05), (Tablo 9).

Tablo 7. Tekrar yatışlarda mortalite YBÜ yatış günü ilişkisi

\begin{tabular}{lcc}
\hline Gün & Taburcu (\%) & Ölüm (\%) \\
\hline $1-2$ & $11(\% 16,18)$ & $10(\% 14,71)$ \\
$3-5$ & $13(\% 19,12)$ & $3(\% 4,41)$ \\
$6-9$ & $9(\% 13,24)$ & $4(\% 5,88)$ \\
$10-19$ & $2(\% 2,94)$ & $5(\% 7,35)$ \\
$2-29$ & $7(\% 10,29)$ & $0(\% 0,0)$ \\
30 ve üzeri & $2(\% 2,94)$ & $2(\% 2,94)$
\end{tabular}

Tablo 8. YBÜ ilk ve tekrar yatışların mortalite oranları

\begin{tabular}{lcccc}
\hline & Taburcu & Ölen & Toplam & Mortalite \% \\
\hline Illk yatış & 1219 & 792 & 2011 & 39,38 \\
Erken tekrar yatı̧̧ & 3 & 7 & 10 & 70,00 \\
Geç tekrar yatı̧̧ & 41 & 17 & 58 & 29,31 \\
Hastane & 1219 & 44 & 1263 & 3,48 \\
Toplam & 1263 & 816 & 2079 & 39,25
\end{tabular}


Tablo 8. Illk ve tekrar yatışlarda ölen ve taburcu olan hastaların Mortalite- Morbidite Skorları (ort. skor \pm SS)

\begin{tabular}{lcccc}
\hline & & Ölen & & Taburcu \\
& ilk yatış & Tekrar yatış & ilk yatış & Tekrar yatış \\
\hline APACHE II & $18,08 \pm 4,28$ & $22,88 \pm 6,02$ & $17,27 \pm 4,42$ & $20,25 \pm 6,09$ \\
SOFA & $4,96 \pm 2,01$ & $7,76 \pm 2,44$ & $4,78 \pm 2,46$ & $5,87 \pm 2,97$ \\
GKS & $6,88 \pm 4,37$ & $7,24 \pm 4,11$ & $10,79 \pm 4,33$ & $10,20 \pm 4,52$
\end{tabular}

\section{Tartışma}

Günümüzde bir hastanede bulunması gereken yoğun bakım yatağı sayısı \%5 olarak belirlenmiştir (1). Sağlık Bakanlığı 02.07.2010 tarihli ve 27132 (2010/50) sayılı Yoğun Bakım Üniteleri'nin planlanması konulu genelgede ise erişkin nüfusu 800,000 'in üzerinde olan sağlık bölge merkezi konumundaki illerde her 10,000 nüfus için 3 yoğun bakım yatağı ve her 20,000 çocuk için 1 adet çocuk yoğun bakım yatağı öngörülmüştür.

Günümüzde YBÜ bulunan her kurum, üniteye hasta kabulü ve taburcu edilmesi ile ilgili kendi kriterlerini belirlemektedir. Ancak yoğun bakım hekimleri hastaların kabul ya da taburcu kararını vermekte zaman zaman zorlanmaktadır. Hastalığın prognozu ve şiddeti, tedavi gereksinimlerinin yanında kaynaklar, personel sayısı, yatak kapasitesi, ailenin baskısı ve alternatif bakım olanaklarının varlığı bu kararı etkilemektedir.

Çalışmalarda tekrar yatış oranları \%5-17,5 gibi çok geniş bir yelpazeye yayılmıştır $(2,3,4,5,6)$. Çalışmamızda toplam tekrar yatış oranı \%3,38 olup yıllara göre dağılımın giderek azaldığı görüldü.

Yaş dağılımı incelendiğinde sırasıyla 8.,7.ve 1. dekatlarda hasta sayısının en fazla olduğu görüldü. Benzer çalışmalardan farklı olarak birinci dekatta hasta sayısının fazla olmasının sebebi hastanemiz bünyesinde ayrıca pediatrik YBÜ bulunmamasıdır $(7,8,9)$.

Klimasaukas ve ark. (10) üç ayrı hastanenin çok disiplinli YBÜ'nde üç yıllık dönemde 13343 hastayı geriye dönük olarak değerlendirmişlerdir. Yeniden yatışlarda erkek hasta sayısı kadınlardan fazla iken, mortalitenin kadınlarda daha yüksek olduğu tespit edilmiştir. Cinsiyet, 70 yaş üstü, 24-48 saatten önce tekrar yatış, hastanede uzun süre yatmış olma mortaliteyle ilişkilendirilmiştir. Ancak bizim çalışmamızda hastaların cinsiyet dağılımı benzer olup mortalite ile ilişkilendirilememiştir.

Çalışmamızda tekrar yatış endikasyonlarında en sık neden mevcut hastalığın tekrar kötüleşmesi ve postoperatif takip idi. Çalışmalarda hasta grupları çok farklı olduğundan yatış endikasyonları da çeşitlilik göstermektedir. Amin ve ark. (2) yeniden yatış nedenlerini, mevcut hastalığın kötüleşmesi veya tekrarlaması, ilk yatışla ilgisiz yeni komplikasyon ve tekrarlayan operasyonlar için takip amaçlı olarak belirlemişlerdir. Rosenberg ve ark.'ın (11) çalışmasında ise kötü tedavi sonucunda hastalığın şiddetinin artması, bir başka hastanenin yoğun bakım ünitesinde yapılan yanlış ve hatalı tedaviler yeniden yatış sebebi olarak gösterilmiştir. Klimasauskas ve ark. (10) yeniden yatışların basit belirleyicisi olarak 70 yaş üstü, 24 saat içinde tekrar yatış ve diğer servislerde uzun süreli yatışların sayılabileceğini belirtmişlerdir. Kardiyovasküler sistem ve solunumsal problemler önemli sorunlar olarak gösterilmiştir (12).

Çalışmamızda 12 hastanın "weaning" sonrası 24 saat içinde ilgili servise gönderildiği görülmektedir. Bu durum özellikle ilk yıl daha yüksek oranda olup bunun sebebinin, önceleri daha az olan yoğun bakım yatak sayısının mevcut talebi karşılayamaması ve yeni başvuruların yoğunluğu olabileceği kanaatindeyiz. Rosenberg ve ark.'nın (4) 1966-1999 yılları arasında YBÜ yeniden yatışları inceledikleri çalışmada, en sık pulmoner ve kardiyovasküler problemlerin yeniden yatışa neden olduğu gösterilmiştir. Gajic ve ark. (13) YBÜ'ne yeniden yatış nedenlerini; yoğun bakım kalış süresi, taburcu günü düşük Glasgow koma skoru ve solunumsal bozukluklar olarak değerlendirmişlerdir. Odetola ve ark.(14) pediatrik YBÜ'ne tekrar yatışları etkileyen faktörleri yaş, acil endikasyonla yatışının yapılması, hastanın kabulünde kliniğinin ağırlığı ile ilişkilendirmişlerdir.

Çalışmamızda erken yeniden yatışlardaki hastaların mortalitesi, geç yeniden yatışlara göre daha fazla bulunmuştur. Bu durumun, hastaların yoğun bakım ünitesinden erken taburcu olmasından ve devredildiği serviste yeterli bakımın yapılamamasından kaynaklandığı düşünülmektedir. RodrigezCarvajal ve ark (15) yaptıkları ileri dönük çalışmalarında 6 yıllık süreçte yoğun bakım ünitesine tekrar yatırılan hastaların önceki yatışlarını incelemişler ve yoğun bakım ünitesinden erken çıkışın mortaliteyi etkileyen önemli bir faktör olduğunu bildirmişlerdir. Rosenberg ve ark (4) yoğun bakımdan taburcu olduktan sonraki ilk 48 saatte tekrar yatışların erken taburculuğu gösterdiğini vurgulamışlardır. Çalışmalarında hastaların \%22-30'unu erken taburcu olarak bulmuşlardır. Campbell ve ark (5) ise YBÜ'ne tekrar yatışların yoğun bakımın kalitesini gösteren bir belirteç olduğunu belirtmişlerdir. Erken yeniden yatışlar (48 saatten önce) erken taburculuğu ya da uygun olmayan klinikle taburculuğu gösterdiğini ifade etmişlerdir. Badawi ve ark. (16) çok merkezli geriye dönük bir çalışma verilerinden yararlanarak YBÜ'den taburcu olduktan sonra ölüm ve YBÜ'ne tekrar yatış ölçeklerini tahmin etmek için bir model geliştirmişlerdir. Bu model, ölüm riskini ve yoğun bakım ünitesinden çıktıktan sonraki ilk dört günde komplikasyon çıkma olasılığını belirlemede başarılı bulunmuştur.

Sonuç olarak; yoğun bakım üniteleri için yatış ve çıkış kriterlerini ayrıntılı olarak belirlemek, hizmet sunumunda kaliteyi 
yükseltecektir. Ancak yatak sayısının intiyacı karşılayamaması nedeniyle bazen erken taburculuk söz konusu olabilmektedir. Daha önemlisi; bir yoğun bakım hastasının YBÜ'den çıktıktan sonra bir süre daha yakın takip edilmesi gerekebilmektedir. Bu gibi durumlarda "Yakın Bakım Üniteleri" nin varlığı YBÜ'ne tekrar yatışları azaltabilecektir.
Çalışmamızın verileri bu açıdan incelendiğinde yoğun bakım ünitesine tekrar yatışın önemli nedenlerinden biri olduğunu düşündüğümüz erken taburcu durumunda hastanın bir süre daha yakın takip ve tedavisinin yapılabileceği " Yakın Bakım Üniteleri"nin oluşturulmasıyla yeniden yatışları azaltmanın mümkün olacağı kanaatindeyiz.

\section{Kaynaklar}

1. Akpir K, Yoğun Bakım Serüveni: Dün, Bugün. Yoğun Bakım Derneği Dergisi, 2002;1: s 6 -7.

2. Amin N, Agarwal V, Kulkarni AP. Readmissions in a surgical intensive care unit: patient characteristics and outcome, IJCCM, January-March 2003, vol 7, p 1.

3. Alex J, Shah R, Griffin SC, Cale AR, Cowen $M E$, Guvendik L. Intensive care unit readmission after elective coronary artery bypass grafting. Asian Cardiovasc Thorac Ann 2005;13:325-9.

4. Rosenberg AL, Watts C. Patients readmitted to ICUs* : a systematic review of risk factors and outcomes. Chest 2000;118:492-502.

5. Campbell AJ, Cook JA, Adey G, Cuthbertson $\mathrm{BH}$. Predicting death and readmission after intensive care discharge. Br J Anaesth 2008;100:656-62.

6. Chan K, Tan CK, Fang CS, Tsai CL, Hou CC, Chenge $\mathrm{KC}$, et al. Readmission to the intensive care unit: An indicator that reflects the potential risks of morbidity and mortality of surgical patients in the intensive care unit. Surgery Today 2009;39:295-9.
7. Uysal N, Gündoğdu N, Börekçi Ş, Dikensoy Ö, Bayram N, Uyar M, ve ark. Üçüncü basamak merkezde dahili yoğun bakım hastalarının prognozu. Dahili ve Cerrahi Bilimler Yoğun Bakım Derg 2010;1:1-5.

8. Moran JL, Bristow P, Solomon PJ, George C, Hart GK; Australian and New Zealand Intensive Care Society Database Management Committee (ADMC). Mortality and lenght-of-stay outcomes, 1993-2003, in the binational Australian and New Zealand intensive care adult patient database. Crit Care Med 2008;36:46-61.

9. Samalavicius R, Urbonas K. ICU Readmission after coronary artery bypass grafting: risk factors and outcomes. Seminars in Cardiovascular Medicine 2007;13:1

10. Klimasauskas A, Kekstas G. Simple prediction of mortality in case of readmission to the intensive care unit. 27th International Symposium on Intensive Care and Emergency Medicine. Brussels, Belgium, 27-30 March 2007 Crit Care 2007; vol 11, sup 2.

11. Rosenberg AL, Hofer TP, Hayward RA, Strachan C, Watts CM. Who bounces back? Physiologic and other predictors of intensive care unit readmission. Crit Care Med 2001;29:511-8.
12. Seferian EG, Afessa B, Gajic O, Keegan MT, Hubmayr RD; Mayo Epidemiology and Translational Research in Intensive Care. Comparison of community and referral intensive care unit patients in a tertiary medical center: Evidence for referral bias in the critically ill. Crit Care Med 2008;36:2779-86.

13. Gajic $\mathrm{O}$, Malinchoc M, Comfere TB, Harris MR, Achouiti A, Yilmaz M, et al. The stability and workload index for transfer score predicts unplanned intensive care unit patient readmission: initial development and validation. Crit Care Med 2008;36:676-82.

14. Odetola FO, Clark SJ, Dechert RE, Shanley TP. Going back for more: An evaluation of clinical outcomes and characteristics of readmissions to a pediatric intensive care unit. Pediatr Crit Care Med 2007;8:343-7.

15. Rodríguez-Carvajal M, Mora D, Doblas A, García M, Domínguez P, Tristancho A, at al. Impact of the premature discharge on hospital mortality after a stay in an intensive care unit. Med Intensiva 2011;35:143-9.

16. Badawi O, Breslow MJ. Breslow Readmissions and Death after ICU Discharge: Development and Validation of Two Predictive Models. PLoS One 2012; 7:e48758. 